\title{
Uncovering how low-molecular-weight carrageenan triggers an immune response
}

\author{
Alexandre H. Lopes \\ Rangel L. Silva \\ Miriam D. Fonseca \\ Francisco I. Gomes \\ Alexandre G. Maganin \\ Lucas S. Ribeiro \\ Lucas Maciel Mauriz Marques \\ Fernando Q. Cunha \\ Jose C. Alves-Filho \\ Dario S. Zamboni \\ Norberto P. Lopes \\ Bernardo S. Franklin \\ Aurélie Gombault \\ Fernando Silva Ramalho \\ Valerie FJ Quesniaux \\ Isabelle Couillin \\ Bernhard Ryffel \\ Thiago M. Cunha
}

Video Byte

Keywords: carageenan, seaweed, cytokine, immune response, inflammation, TLR, IL-1, TNF, Cell Communication and Signaling

Posted Date: November 11th, 2020

DOl: https://doi.org/10.21203/rs.3.rs-106078/v1

License: (1) This work is licensed under a Creative Commons Attribution 4.0 International License. Read Full License 


\section{Abstract}

Low-molecular-weight carrageenan $(\mathrm{Cg})$ is a seaweed-derived sulfated polysaccharide that has been widely used to stimulate inflammation in preclinical studies. However, exactly how $\mathrm{Cg}$ induces inflammation is still unclear. Using cell culture and mouse model experiments, investigators examined the molecular basis of two inflammatory processes triggered by $\mathrm{Cg}$ : macrophage activation and cytokine production. Mouse peritoneal macrophage primary cell cultures were stimulated with a form of $\mathrm{Cg}, \mathrm{k}-\mathrm{Cg}$. The researchers found that $\mathrm{K}-\mathrm{Cg}$ activates peritoneal macrophages to produce pro-inflammatory cytokines such as TNF and IL-1 $\beta$. While $\mathrm{k}-\mathrm{Cg}$-induced TNF production and secretion depend on TLR4/MyD88 signaling, the production of pro-IL-1 $\beta$ relies on the TLR4/TRIF/SYK/ reactive oxygen species signaling pathway. Furthermore, pro-IL1 $\beta$ maturation to IL-1 $\beta$ is dependent on canonical NLRP3 inflammasome activation via Pannexin-1/P2X7/K+ efflux signaling, and in a $\mathrm{K}$-Cg-induced colitis mouse model, colitis was reduced in the absence of NLRP3 inflammasome components. The results of this study indicate a critical role of the NLRP3 inflammasome in Cg-induced pro-inflammatory cytokine production and colitis, which clarifies some of the pro-inflammatory properties of $\mathrm{Cg}$ for pre-clinical studies. 